\author{
Abstracta Iranica \\ Abstracta Iranica Revue bibliographique pour le domaine irano-aryen \\ Volume 37-38-39 | 2018 \\ Comptes rendus des publications de 2014-2016
}

\title{
Desmond Durkin-Meisterernst. Miscellaneous Hymns. Middle Persian and Parthian Hymns in the Turfan Collection
}

\section{Agnes Korn}

\section{(2) OpenEdition \\ Journals}

Édition électronique

URL : http://journals.openedition.org/abstractairanica/43009

DOI : 10.4000/abstractairanica.43009

ISBN : 1961-960X

ISSN : 1961-960X

Éditeur :

CNRS (UMR 7528 Mondes iraniens et indiens), Éditions de l'IFRI

\section{Référence électronique}

Agnes Korn, « Desmond Durkin-Meisterernst. Miscellaneous Hymns. Middle Persian and Parthian Hymns in the Turfan Collection », Abstracta Iranica [En ligne], Volume 37-38-39 | 2018, document 8, mis en ligne le 30 décembre 2018, consulté le 27 septembre 2020. URL : http://journals.openedition.org/ abstractairanica/43009; DOI : https://doi.org/10.4000/abstractairanica.43009

Ce document a été généré automatiquement le 27 septembre 2020.

Tous droits réservés 


\section{Desmond Durkin-Meisterernst. Miscellaneous Hymns. Middle Persian and Parthian Hymns in the Turfan Collection}

Agnes Korn

\section{RÉFÉRENCE}

Desmond Durkin-Meisterernst. Miscellaneous Hymns. Middle Persian and Parthian Hymns in the Turfan Collection. Turnhout, Brepols, 2014, 443 p. +12 planches (Berliner Turfantexte, XXXI).

1 Le présent volume s'inscrit dans un projet à long terme mené par le Département de recherches sur le Tourfan de l'Académie des Sciences à Berlin, qui consiste dans l'édition des fragments manichéens trouvés au Turkestan chinois au début du XX siècle. En ce qui concerne les fragments en moyen-perse et parthe, chaque volume de la série Berliner Turfantexte est consacré à des textes appartenant à des rubriques de sujet ou genre telles qu'ils ont été établis par Mary Boyce dans l'annexe de son catalogue (A Catalogue of the Iranian manuscripts in Manichean script in the German Turfan collection, Berlin 1960), voir des comptes rendus d'autres volumes de la série dans les numéros précédents d'Abstracta Iranica (cr dans le volume 34-35-36 et cr dans le volume 32-33).

Dans ce cadre, le présent ouvrage comprend l'édition de plus de 250 fragments en moyen-perse et en parthe que Boyce avait attribués aux groupes de textes suivants : hymnes adressées au "Troisième messager " (une divinité lumineuse appelée aussi Narisah Yazd ou Mihr Yazd), hymnes en couplets, hymnes non-classifiées et poèmes. La grande majorité des fragments présentés dans cette édition n'avait pas été publiée auparavant. Évidemment, si la très vaste majorité appartient aux collections qu'abritent à Berlin l'Académie des Sciences et le Musée des Arts asiatiques (Museum 
für Asiatische Kunst), l'A. a également inclus quelques fragments se trouvant dans des collections à l'étranger (à Saint-Pétersbourg et la collection Otani au Japon).

L'introduction donne donc les listes des fragments appartenant à chaque groupe d'hymnes (p. 2-16) avec (le cas échéant) des références aux publications antérieures, ainsi qu'une liste (p. 17-22) de tous les fragments édités dans ce volume. La partie principale (p. 24-381) contient sur la page de gauche la translittération des fragments ligne à ligne, et (à droite) l'arrangement du texte en versets avec leur traduction en anglais.

4 Le glossaire (p. 387-442) répertorie tous les mots attestés dans les fragments de ce volume dans une seule liste comme c'est la tradition dans les études manichéennes (par ex. dans le dictionnaire par l'A., Dictionary of Manichaean Middle Persian and Parthian, Turnhout 2004) car un bon nombre de mots sont communs au moyen-perse et au parthe.

5 La tâche à laquelle s'est trouvé confronté l'A. consistait dans le déchiffrement et l'analyse du contenu (rappelons qu'une partie des fragments est minuscule et ne contient que quelques mots). Ses efforts ont permis non seulement la traduction, mais tout d'abord l'arrangement des fragments en hymnes (parfois la taille de l'écriture donne des indices quant à l'appartenance de tel ou tel fragments à un texte) et leur séquence (en ceci, et là où le début du verset est préservé, l'A a été aidé par le fait que beaucoup d'hymnes sont de structure abécédaire, chaque verset commençant par une lettre dans l'ordre de l'alphabet manichéen). Son analyse a par ailleurs amené l'A. à proposer des modifications par rapport au classement établi par Boyce d'un certain nombre de fragments, qui désormais sont attribués à un autre groupe de textes.

Des photos de haute qualité des manuscrits manichéens de Berlin étant disponibles sur http://turfan.bbaw.de/dta/m/dta_m_index.htm, le volume ne fournit que des photos de fragments que l'A. estime appartenir à la même page, et qui depuis ont été dispersés en divers endroits, inventoriés sous des numéros donnés au gré des hasards de leur inventoriage.

7 Le travail philologique minutieux et impressionnant entrepris par l'A. a donné un ensemble de presque 5000 lignes de texte, contribuant ainsi de façon significative à l'élargissement $d u$ corpus de textes manichéens en moyen-perse et en parthe disponibles.

\section{AUTEURS}

\section{AGNES KORN}

CNRS, Mondes iranien et indien, Paris 